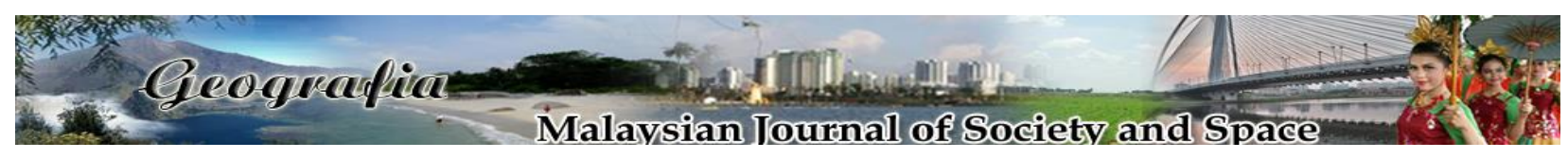

\title{
Kualiti keusahawanan dalam kalangan usahawan kecil dan sederhana
}

\author{
Mohd. Raiz Razuan ${ }^{1}$, Zaimah, R. ${ }^{2}$, Sarmila, M.S. ${ }^{2}$, Abd Hair Awang ${ }^{2}$ \\ ${ }^{1}$ Pejabat Daerah/Tanah Hulu Langat, Kompleks Pentadbiran Daerah, Bandar Baru Bangi, Selangor \\ ${ }^{2}$ Program Sains Pembangunan, Pusat Pembangunan, Sosial dan Persekitaran, \\ Fakulti Sains Sosial dan Kemanusiaan, Universiti Kebangsaan Malaysia \\ Correspondence: Zaimah, R. (email: zaimahr@ukm.edu.my)
}

Received: 01 April 2019; Accepted: 23 April 2019; Published: 22 August 2019

\begin{abstract}
Abstrak
Kualiti keusahawanan amat penting dalam menjamin kejayaan seseorang usahawan. Kualiti keusahawanan boleh diukur berdasarkan faktor keperibadian dan orientasi keusahawanan. Selain itu, pelbagai program pembangunan usahawan yang dilaksanakan oleh pihak berkepentingan boleh dijadikan kayu ukur kepada kualiti keusahawanan. Namun begitu, setiap usahawan tidak bersifat homogeneus kerana mereka mempunyai keperibadian, orientasi dan persekitaran yang berbeza antara satu sama lain. Objektif kajian adalah mengukur tahap kualiti keusahawanan dan mengenal pasti hubungan di antara faktor keperibadian, orientasi dan program pembangunan usahawan dengan kualiti keusahawanan yang dimiliki oleh usahawan kecil dan sederhana di Lembaga Kemajuan Johor Tenggara (KEJORA). Kajian ini menggunakan pendekatan kuantitatif dan kaedah survei. Sampel kajian adalah usahawan kecil dan sederhana yang berdaftar dengan KEJORA. Teknik persampelan rawak mudah digunakan dalam pemilihan sampel. Hasilnya, seramai 101 usahawan kecil dan sederhana terlibat dalam kajian ini. Instrumen pengutipan data adalah menggunakan borang soal selidik. Statistik diskriptif dan inferensi (korelasi PointBiserial) digunakan bagi menjawab objektif kajian. Hasil kajian menunjukkan tahap kualiti keusahawanan usahawan adalah sederhana. Faktor keperibadian, orientasi dan program pembangunan usahawan didapati mempunyai hubungan dengan kualiti keusahawanan usahawan di KEJORA. Dalam pada itu, faktor orientasi didapati mempunyai hubungan paling penting dalam menetapkan tahap kualiti keusahawanan usahawan. Hal ini menunjukkan bahawa usahawan yang beroperasi di KEJORA mempunyai keupayaan keusahawanan sebenar. Sehubungan itu, pihak berkepentingan perlu memperbaiki program pembangunan sedia ada agar lebih menepati keperluan semasa usahawan di KEJORA. Golongan muda yang mempunyai kelulusan di peringkat universiti juga perlu digalakkan menjadi usahawan agar kualiti keusahawanan usahawan kecil dan sederhana boleh ditingkatkan.
\end{abstract}

Kata kunci: inisiatif, inovasi, kolaborasi, kualiti keusahawanan, perniagaan, usahawan 


\title{
Quality of entrepreneurship in small and medium entrepreneurs
}

\begin{abstract}
Quality of entrepreneurship is very essential in ensuring the success of an entrepreneur. Entrepreneurship quality can be measured based on personality and entrepreneurial orientation factors. In addition, entrepreneur development programs implemented by stakeholders can be used as a measure of entrepreneurial quality. However, every entrepreneur is not homogeneous because they have different personality, orientation and environment. The objective of the study is to measure the level of entrepreneurial quality and to identify the relationship between personality, orientation and entrepreneur development program with the entrepreneurial qualities of the small and medium entrepreneurs at the Southeast Johor Development Authority (KEJORA). This study uses a quantitative approach and a survey method is employed. Sample of research are the small and medium entrepreneurs registered with KEJORA. Simple random sampling techniques have been used in sample selection, resulting in 101 small and medium entrepreneurs being selected for this study. The data collection instrument is using questionnaire. Descriptive and inferential statistics (Point-Biserial correlation) are used to answer the objective of the study. The results show that the entrepreneurship quality is moderate among the entreprenuer. The personality factor, orientation and entrepreneur development program are found to have a relationship with the entrepreneurial quality among entrepreneurs in KEJORA. The orientation factor is found to have the most important relationship in determining the entrepreneurial quality level of an entrepreneur. This shows that entrepreneurs operating in KEJORA have real entrepreneurial capabilities. In this regard, stakeholders should improve the development programs to better meet the current needs of the entrepreneurs in KEJORA. The youth with university qualification should also be encouraged to become entrepreneurs so that the entrepreneurial qualities of small and medium entrepreneurs can be improved.
\end{abstract}

Keywords: initiative, innovation, collaboration, entrepreneurship quality, business, entrepreneurs

\section{Pengenalan}

Keusahawanan merupakan penyumbang utama dalam ekonomi sesebuah negara di seluruh dunia. Namun begitu, terdapat perbezaan signifikan antara kualiti dan kuantiti keusahawanan di negara maju dan negara sedang membangun, khususnya dari dimensi institusi formal dan institusi tidak formal (Chowdry et al., 2019). Malahan akhir-akhir ini, bidang keusahawanan dikenal pasti sebagai salah satu alternatif utama dalam penciptaan peluang pekerjaan (Kautonen et al., 2017) daripada terus bergantung atau mengharap bekerja makan gaji. Dalam hal ini, kualiti keusahawanan perlu diberi perhatian dan tidak boleh diabaikan (Zhenfeng \& Ming, 2017). Kualiti keusahawanan menunjukkan dua elemen penting dalam usaha menjadi usahawan yang berkualiti, iaitu keperibadian diri (sosiologi), orentasi keusahawanan (psikologi) serta persekitaran (Guzman \& Santos, 2001; Zhou et al., 2012), seperti polisi dan dasar kerajaan dalam melaksanakan program pembangunan usahawan. 
Kerajaan Malaysia telah melaksanakan pelbagai dasar dan inisiatif untuk membangunkan golongan usahawan luar bandar. Kerajaan telah melancarkan Pelan Induk Perusahaan Kecil dan Sederhana (PKS) 2012-2020 untuk memberikan hala tuju dan penumpuan yang lebih fokus bagi melahirkan golongan usahawan yang berkualiti, berdaya tahan dan mampu bersaing dengan perusahaan luar negara (Malaysia, 2015). Pelbagai program sokongan perniagaan dan program pembangunan usahawan telah dilaksanakan, seperti pembiayaan perniagaan, latihan keusahawanan, pemasaran produk, pembangunan produk dan penjenamaan, pembinaan premis perniagaan dan kilang yang dilaksanakan oleh pelbagai agensi diperingkat pusat dan negeri di seluruh negara. Namun, segala yang diusahakan ini hanya akan mencapai kejayaan sekiranya usahawan PKS yang dibangunkan mempunyai kualiti diri, seperti persiapan diri yang mencukupi dan daya pemikiran yang berorentasikan keusahawanan seperti inovatif, kreatif, proaktif dan berani mengambil risiko perniagaan (Abdullah et al., 2018). Kualiti yang ada pada seseorang usahawan ini akan menentukan kejayaan terhadap inisiatif dan program yang dijalankan oleh pihak kerajaan.

Pada tahun 2012, kerajaan Malaysia melalui agensi SME Corp. telah menjalankan penilaian dan rating bagi mengukur kobolehan usahawan mikro dan PKS untuk menjadi pengusaha yang berdaya saing dan mengembangkan perniagaan di seluruh negara (KKLBW, 2012). Usaha ini dilihat sebagai langkah untuk mengukur kualiti usahawan serta perusahaan yang telah bangunkan oleh semua agensi kerajaan yang melaksanakan Program Pembangunan Usahawan di Malaysia. Dapatan awal kajian ini menunjukkan bahawa hanya 20 peratus PKS di Malaysia mendapat pengiktirafan sekurang-kurangnya tiga bintang daripada maksimum lima bintang. Sementara itu, hanya seorang usahawan PKS sahaja yang mendapat pengiktirafan satu bintang daripada 500 usahawan yang dibangunkan oleh Wilayah Kemajuan Johor Tenggara (KEJORA).

Sehubungan itu, artikel ini mempunyai dua objektif, iaitu mengukur tahap kualiti keusahawanan dalam kalangan usahawan KEJORA dan mengenal pasti hubungan kualiti keusahawanan dengan keperibadian usahawan, orientasi usahawan dan program pembangunan usahawan KEJORA.

\section{Kajian literatur}

Kajian lepas telah banyak menyentuh tentang faktor yang menyumbang kepada pencapaian usahawan dan perniagaan, sama ada oleh pengkaji dalam atau luar negara. Perkara yang sering dibincangkan adalah berkenaan pengurusan perniagaan, operasi perniagaan dan potensi perniagaan yang dijalankan bagi mencapai keuntungan dan pertumbuhan perniagaan. Santos dan Francisco (2002) mendapati tahap kualiti kusahawanan dipengaruhi oleh keperibadian usahawan, seperti tahap pendidikan, pengalaman perniagaan dan pengaruh keluarga yang asalnya juga seorang peniaga. Sebaliknya, faktor persekitaran seperti polisi dan program yang dijalankan kerajaan kurang mempengaruhi tahap kualiti keusahawanan. Namun, Santos et al. (2012) mendapati wujud hubungan di antara pertumbuhan dan kemajuan sesebuah wilayah pembangunan ekonomi dengan kualiti keusahawanan.

Kajian Darroch dan Clover (2005) menunjukkan kebolehan seseorang usahawan membuat pinjaman dan membayar balik pinjaman secara konsisten adalah bergantung kepada kualiti keusahawanan. Kajian ini menunjukkan bahawa usahawan yang mempunyai kualiti keusahawanan yang baik mempunyai orentasi usahawan, mewarisi perniagaan keluarga dan cenderung untuk menyelesaikan pinjaman perniagaan mengikut jadual. Kajian Manaf et al., 
(2012) yang melihat kepada faktor-faktor kritikal penentu kejayaan usahawan berdasarkan tahap penglibatan, keuntungan dan jenis perniagaan yang diceburi. Manakala Osman (2007) juga telah melihat faktor-faktor kritikal yang mempengaruhi kejayaan dan kegagalan usahawan TEKUN. Perbincangan tersebut berfokus kepada bidang perniagaan yang dipilih, kesesuaian penempatan perusahaan dijalankan dan bentuk pembiayaan TEKUN yang memudahkan peminjam untuk membayar balik pinjaman mereka.

Sementara Yaacob (2012) telah membincangkan berkenaan model usahawan berjaya daripada aspek strategi perniagaan, kelebihan sumber bahan mentah, pengalaman dalam perniagaan, pengalaman bekerja dalam bidang yang sama, berkeyakinan dan bermotivasi. Manakala, Wan Hussain (2005) menerangkan tentang bentuk pengurusan yang perlu ada bagi membentuk perusahaan yang berjaya. Bentuk pengurusan adalah sebahagian daripada aspek yang perlu dilihat bagi melihat kualiti dan kejayaan seseorang usahawan. Selain itu, aspek luaran yang turut mempengaruhi kualiti keusahawanan adalah peranan kerajaan dalam menetapkan polisi dan melaksanakan program pembangunan usahawan (Guzman \& Santos, 2001), seperti menyediakan kemudahan kepada usahawan melalui program latihan keusahawanan, pemasaran dan promosi produk, pembiayaan perniagaan dan pembinaan premis perniagaan. Kemudahankemudahan tersebut merupakan sebahagian daripada masalah yang sering dihadapi oleh usahawasan PKS (Diana et al., 2015).

\section{Kualiti keusahawanan}

Kualiti keusahawanan adalah satu konsep yang berpunca daripada konsep sfera fungsi usahawan yang dipelopori oleh Guzman (1994). Konsep ini menjelaskan bahawa terdapat tiga sfera fungsi usahawan, iaitu fungsi pengurusan, fungsi kewangan dan fungsi penggalak. Fungsi pengurusan dan fungsi kewangan dianggap sebagai fungsi usahawan yang menjadi rutin dan mesti dilakukan oleh setiap usahawan. Manakala, fungsi penggalak merupakan tahap pencapaian seseorang usahawan. Fungsi penggalak dibahagikan kepada dua sub-fungsi, iaitu sub-fungsi penaja dan sub-fungsi perangsang. Sub-fungsi penaja sering kali dikaitkan dengan bakal usahawan yang dibangunkan dan pertambahan bilangan usahawan. Manakala, sub-fungsi perangsang pula melihat kepada sikap, pemikiran dan tingkah laku keusahawanan sebenar yang meliputi faktor keperibadian usahawan, orientasi keusahawanan dan persekitaran yang dihadapi oleh setiap usahawan. Sub-fungsi perangsang juga dirujuk sebagai kualiti keusahawanan (Guzman \& Santos, 2001).

Secara mudah, kualiti keusahawanan merupakan satu konsep yang mengukur kecemerlangan usahawan yang dibentuk oleh faktor diri usahawan. Kualiti keusahawanan dilihat daripada faktor keperibadian usahawan dan orientasi keusahawanan yang menjadi pegangan usahawan. Orientasi keusahawanan dan keperibadian usahawan seperti tahap pendidikan, pengalaman menjalankan perniagaan dan motivasi menjadi usahawan perlu dikaji secara bersama bagi mengukur tahap kualiti keusahawanan (Cooper \& Dunkelberg, 1987). Santos et al. (2012) telah menyatakan bahawa kualiti keusahawanan adalah inisiatif dan tingkah laku usahawan dalam memajukan perusahaannya. Kajian mereka juga melihat kepada faktor luaran yang mempengaruhi kualiti keusahawanan dengan mengambilkira keadaan persekitaran perniagaan dan intervensi daripada pihak Kerajaan. Kerajaan boleh membangunkan usahawan melalui program inkubator, latihan keusahawanan, pembinaan premis perniagaan dan bantuan pembiayaan kewangan kepada PKS (Santos et al., 2012). 
Bagi mengukur sub-fungsi perangsang, perlakuan seseorang usahawan perlu dilihat dan dinilai daripada segi cita-cita perniagaan, inovasi, kolaborasi dan inisiatif perniagaan yang telah dicapai dan juga rancangan pada masa hadapan usahawan berkenaan. Perincian keempat-empat aspek tersebut adalah seperti berikut:

a. Cita-cita perniagaan merujuk kepada kecenderungan usahawan untuk meningkatkan saiz perniagaannya. Pertumbuhan saiz perniagaan ini tidak hanya dilihat kepada perolehan keuntungan semata-mata, tetapi turut meliputi kemampuan menguasai pasaran dan peningkatan status sosial (Guzman, 1995).

b. Inovasi merujuk kepada usaha yang dijalankan oleh usahawan bagi meningkatkan perniagaan mereka melalui inovasi produk baru dan kreativiti dalam menjalankan aktiviti perniagaan. Inovasi yang dilakukan bukan sahaja bagi menghasilkan produk yang lebih baik, tetapi juga melibatkan teknik pengeluaran, pengurusan, bahan mentah dan pasaran baru (McCaffrey, 2009).

c. Kolaborasi merujuk kepada kerjasama dalam perniagaan di antara pengusaha dalam bidang yang sama, membuat jaringan bersama pelanggan, perusahaan lain dan pengeluaran bahan mentah. Kerjasama yang dilakukan adalah bertujuan mendapatkan kelebihan teknik atau menjadi lebih kompetatif (McCaffrey, 2009). Usahawan yang mempunyai rangkaian jaringan menunjukkan usahawan yang mempunyai tahap kualiti keusahawanan yang tinggi.

d. Inisiatif pula merujuk kepada perancangan yang dibuat secara berterusan bagi mengelak penawaran produk yang hampir sama dalam pasaran dan mewujudkan 'niche' dalam pasaran. Perancangan yang dibuat untuk jangka pendek dan panjang serta membuat strategi yang berkesan boleh menunjukkan indikator kualiti keusahawanan yang tinggi, sederhana atau rendah. Selain itu, inisiatif juga boleh dilihat melalui latihan yang diberikan kepada pekerja yang juga dianggap sebagai aset kepada perniagaan.

\section{Keperibadian usahawan}

Keperibadian usahawan adalah satu faktor yang mempunyai hubungan dengan kualiti keusahawanan. Hubungan tersebut dapat dilihat daripada aspek pengalaman usahawan dalam bidang perniagaan, usahawan yang mewarisi perniagaan keluarga dan keinginan untuk bekerja sendiri. Faktor keperibadian usahawan mempengaruhi nilai keusahawanan dan kebolehan menjadi usahawan yang mempengaruhi kebolehan untuk membuat produk baru dan peluang perniagaan melalui pemikiran yang kritikal, komunikasi yang berkesan, penyelesaian masalah dan kemahiran perundingan yang baik (Herron \& Robinson, 1993). Keinginan untuk bekerja sendiri pula memperlihatkan psikologi usahawan yang ingin bebas, tidak suka dikawal dan tidak suka kepada birokrasi (Darroch \& Clover, 2005). Usahawan yang mempunyai pengalaman perniagaan yang berkaitan bidang perusahaan yang diceburi mampu meningkatkan kualiti keusahawanan seseorang usahawan. Hal ini akan memberi kesan positif ke atas usahawan daripada aspek motivasi dan material kepada kualiti keusahawanan usahawan tersebut.

Keperibadian usahawan juga melihat kepada tahap pendidikan yang akan menentukan tahap kejayaan mereka. Menurut Zafir dan Fazilah (2007), latar belakang pendidikan menjadi salah satu pembolehubah penting bagi mempengaruhi penglibatan masyarakat dalam bidang keusahawanan. Tahap pendidikan yang tinggi akan memberikan lebih peluang untuk menjadi usahawan yang berjaya (Cooper \& Dunkelberg, 1987; Gibb, 1993; Rohani et al., 2016). Kajian 
oleh Stanworth dan Gray (1991) turut mendapati usahawan yang mempunyai tahap pendidikan tinggi mempunyai kemungkinan tinggi untuk mencapai kejayaan dalam perniagaan.

Selain itu, motivasi untuk menjadi usahawan dilihat daripada aspek motivasi intrisik, iaitu menjadi usahawan kerana keadaan ekonomi baik dan jangkaan pulangan perniagaan yang menguntungkan. Motivasi sebegini membentuk perlakuan usahawan yang menggalakkan daya usaha usahawan untuk memajukan perniagaannya. Hal ini juga merujuk kepada cita-cita untuk membesarkan perniagan, membuat inovasi dalam proses pengeluaran dan bekerjasama dengan perusahaan dan individu lain bagi mencapai pertumbuhan dalam perniagaan (Guzman, 1994). Manakala motivasi ekstrisik pula merujuk kepada usahawan yang menceburkan diri dalam bidang perniagaan kerana desakan kesusahan hidup. Motivasi sebegini lebih berbentuk materialistik dan dicerminkan dengan menjalankan pekerjaan yang mudah, semangat keusahawanan berbentuk sementara, minat untuk mempelajari ilmu baru yang rendah dan mempunyai emosi yang negatif (Guzman \& Santos, 2001; Paco et al., 2017).

\section{Orientasi keusahawanan}

Orentasi keusahawanan adalah satu elemen kualiti keusahawanan yang memperlihat ciri-ciri pemikiran dan tingkah laku usahawan yang mampu bersaing di pasaran lebih besar, berani menghadapi persaingan dan boleh membawa perusahaan untuk berjaya. Pada perspektif pengurusan, kualiti keusahawanan adalah elemen penting kepada pertumbuhan dan kejayaan perusahaan (Lumpkin \& Dess, 1996). Orentasi keusahawanan adalah pembentukan multidimensi yang mengukur usahawan yang inovatif, proaktif dan berani mengambil risiko perniagaan dan turut dikenal pasti sebagai indikator kualiti keusahawanan.

Perkara yang dilihat dalam orentasi keusahawanan adalah usahawan yang berinovasi, iaitu memikirkan teknologi dan teknik pemprosesan yang boleh meningkatkan pengeluaran produk serta mengurangkan kos perunit produk. Inovasi bermaksud usahawan cenderong mencari idea baru dan proses kerja yang kreatif (Lumpkin \& Dess, 1996). Asalnya idea inovasi usahawan ini dikembangkan oleh Schumpeter (1934) dalam Theory Creative-Destruction yang mencerminkan sikap inovasi usahawan dalam setiap proses pembangunan (McCaffrey, 2009).

Sikap usahawan yang proaktif pula bermaksud usahawan telah menjangkakan peluang dan halangan terlebih awal dalam menjalankan perusahaan bagi mengurangkan risiko perniagaan dan membuat persediaan daripada segi mental, kewangan dan bahan mentah. Menurut Basso et al. (2016), proaktif bermaksud usahawan yang mengeksploitasi produk baru dan peluang pemasaran lebih awal berbanding pesaing lain. Brown et al. (2001) pula menekankan kepentingan usahawan untuk sentiasa berwaspada dengan halangan dan cabaran luar dalam perusahaan mereka. Manakala Guzman dan Santos (2001) berpendapatan usahawan yang proaktif adalah usahawan yang mengenalpasti polisi strategik yang membawa kepada pertumbuhan perniagaan.

Usahawan yang berani menghadapi risiko adalah mereka yang telah membuat keputusan perniagaan yang membawa pulangan keuntungan dan mengurangkan liabiliti kepada perusahaan. Shane et al. (2012) mendefinisikan risiko sebagai ketidaktentuan akibat keputusan perniagaan yang dilakukan dan ianya merupakan sifat orentasi keusahawanan yang penting. Usahawan yang berani mengambil risiko adalah mereka yang jelas dan mengetahui setiap risiko yang diambil dan telah bersiap sedia jika perancangan yang dibuat menghadapi halangan (Koellinger et al., 2007). Sebaliknya, usahawan yang mempunyai persepsi kegagalan untuk mengambil risiko yang besar berkemungkinan menemui kegagalan mencapai objektif perniagaan. 


\section{Program Pembangunan Usahawan KEJORA}

KEJORA mula menjalankan program pembangunan usahawan dengan kerjasama Kementerian Luar Bandar dan Wilayah (KKLBW) bermula dari tahun 2000. Tujuan program adalah untuk meningkatkan pendapatan dan taraf hidup penduduknya yang terdiri daripada nelayan, pengusaha kelapa sawit dan petani. Program juga diadakan bagi mengurangkan migrasi keluar penduduk ke bandar dengan memberi mereka peluang perniagaan untuk menyara diri dan mampu berdikari dari terus mengharapkan bantuan daripada pihak Kerajaan (KEJORA, 2012). Sebanyak RM30 juta peruntukan disediakan bagi program ini dari tahun 2000 hingga 2013 (KEJORA, 2012). Program yang dijalankan adalah seperti latihan keusahawanan, ekspo dan pemasaran produk, pembiayaan perniagaan SPED, pembinaan premis perniagaan dan pembangunan produk.

Latihan keusahawanan dilaksanakan bagi meningkatkan ilmu pengetahuan dan pelbagai kemahiran usahawan agar dapat membentuk usahawan yang sentiasa bersedia dengan kehendak dan keperluan pasaran. Peserta kursus terdiri daripada bakal usahwan yang berusia muda dan usahawan luar bandar yang sedia ada di KEJORA. Pada tahun 2012, sebanyak 18 siri kursus keusahawanan telah diadakan di sekitar KEJORA yang melibatkan 880 orang peserta (KEJORA, 2013).

Program ekspo dan pemasaran produk pula melibatkan usahawan yang telah menjalankan perusahaan dalam bidang pembuatan dan pemprosesan makanan. Usahawan yang mengikuti program ini akan dibiayai untuk mengikuti ekspo dan karnival dalam dan luar negara. Peserta program berpeluang memperkenalkan produk mereka kepada pelanggan berpotensi di tempat pameran yang strategik, seperti di Pusat Dagangan Dunia Putra (PWTC), MID Valley Exhibition Centre dan Karnival Usahawan Desa anjuran KKLBW. Pada tahun 2012, sebanyak 17 ekspo telah disertai oleh 93 pengusaha KEJORA (KEJORA, 2013).

Program pembangunan produk adalah program yang dijalankan secara usahasama dengan Politeknik Sultan Ibrahim, Johor Bahru dalam beberapa aktiviti seperti penjenamaan semula produk dan syarikat, menaiktaraf pembungkusan produk dan kemaskini sistem pengurusan syarikat. Pada tahun 2012, sebanyak 12 buah syarikat telah mengikuti program ini (KEJORA, 2013).

Pembinaan premis perniagaan adalah program pembinaan gerai perniagaan, bengkel, kilang IKS dan kilang bertaraf piawaian Good Manufacturing Product (GMP) yang dibina di lokasi yang strategik dengan kadar sewa yang minima. Pengusaha akan ditempatkan ke premis perniagaan yang dibina mengikut kesesuaian produk dan perkhidmatan yang dihasilkan. Pengusaha yang menjalankan perusahaan dalam bidang pemprosesan ditempatkan di kilang IKS yang lebih mudah untuk mendapatkan status halal. Hal ini kerana pelan bangunan kilang IKS tersebut selari dengan keperluan Jabatan Kemajuan Islam Malaysia (JAKIM). Sehingga tahun 2014, sebanyak 93 unit premis perniagaan telah dibina di KEJORA (KEJORA, 2015).

Melalui program pembiayaan perniagaan, usahawan KEJORA yang berminat akan memohon pinjaman daripada Skim Pembiayaan Ekonomi Desa (SPED) anjuran KKLBW (KEJORA, 2014). Had kelayakan pembiayaan adalah sehingga RM500,000 dan pinjaman ini berbentuk non-colateral, iaitu tidak perlu jaminan dan cagaran. Bidang yang dibiayai adalah perkhidmatan, pembuatan, pelancongan desa, penternakan dan pertanian. 


\section{Metod dan kawasan kajian}

Kajian dilakukan dalam kalangan usahawan PKS di KEJORA. Objektif penubuhan KEJORA adalah mengurangkan ketidakseimbangan ekonomi, mewujudkan peluang pekerja dan mempercepatkan pertumbuhan ekonomi di wilayah KEJORA. Keluasan wilayah KEJORA meliputi 16 peratus kawasan Negeri Johor dengan jumlah keluasan 300,111 hektar. KEJORA terbahagi kepada dua wilayah, iaitu Johor Tengah dan Pengerang. Semasa kajian dilakukan, KEJORA telah membangunkan seramai 500 orang usahawan yang terdiri daripada usahawan mikro dan PKS. Terdapat enam pengelompokan bandar yang menjadi tumpuan usahawan di Wilayah Pembangunan KEJORA, iaitu Bandar Mas, Bandar Penawar, Bandar Tenggara, Bandar Seri Perani, Bandar Petri Jaya dan Taman Sri Lambak. Kawasan berkenaan menempatkan beberapa jenis PKS, seperti pembuatan makanan, ubat tradisional, syarikat 'contract manufacturing', kedai runcit, kedai makan, kraftangan, bengkel kenderaan, bengkel logam dan pengusaha inap desa.

Kajian ini menggunakan pendekatan kuantitatif dan kaedah survei dipraktiskan. Teknik persampelan rawak mudah dijalankan ke atas 500 usahawan berdasarkan senarai yang diperolehi dari pihak KEJORA. Hasilnya seramai 101 usahawan terpilih menjadi responden, iaitu 20 peratus daripada populasi kajian. Borang soal selidik digunakan sebagai instrumen pengutipan data. Borang soal selidik yang mengandungi maklumat latar belakang responden, latar belakang perusahaan, kualiti keusahawanan, keperibadian, orientasi dan program pembangunan KEJORA. Kualiti keusahawanan mengandungi empat item, iaitu cita-cita perniagaan, inovasi, koloborasi dan inisiatif. Setiap item mempunyai dua soalan, bermakna jumlah semua soalan adalah lapan. Pengukuran item dibuat secara berikut; jawapan 'Ya' diberikan 2 markah dan jawapan 'Tidak' akan diberikan 1 markah. Bermakna skor terendah adalah 8 dan skor tertinggi adalah 16. Seterusnya pengkelasan skor dibuat berdasarkan skor 8 hingga 11 (rendah), skor 12 hingga 14 (sederhana) dan skor 15 hingga 16 (tinggi). Analisis data kajian adalah menggunakan statistik deskriptif dan inferensi. Statistik inferensi digunakan bagi melihat hubungan faktor keperibadian usahawan, orentasi keusahawanan dan program pembangunan usahawan KEJORA dengan tahap kualiti keusahawanan. Analisis korelasi 'Point-Biserial' $\left(\mathrm{r}_{\mathrm{s}}\right)$ amat sesuai digunakan ke atas data deskriptif untuk jawapan 'Ya' atau 'Tidak' yang dikodkan ' 0 ' dan ' 1 ' dengan data yang berpangkat (likert).

\section{Hasil kajian dan perbincangan}

Bahagian ini menjelaskan tentang profil responden, profil perniagaan, tahap kualiti keusahawanan, hubungan keperibadian usahawan dengan tahap kualiti keusahawanan, hubungan orentasi keusahawanan dengan tahap kualiti keusahawanan, dan hubungan program pembangunan usahawan dengan tahap kualiti keusahawanan.

\section{Profil responden}

Jadual 1 menunjukkan profil responden. Hasil kajian menunjukkan majoriti responden adalah lelaki $(71.3 \%)$ dan kebanyakan responden juga telah berkahwin (91.1\%). Rata-rata responden mempunyai bilangan anak antara satu hingga empat orang (81.2\%). Hampir separuh daripada responden adalah dalam kategori belia (41.6\%) dan lebih ramai responden berumur lebih 40 
tahun (58.4\%). Jika dilihat kepada tahap pendidikan pula, responden paling ramai mendapat Sijil/Pendidikan Vokasional (44.6\%), diikuti oleh responden yang mempunyai pendidikan sekurang-kurangnya Sekolah Menengah/Sekolah Rendah (41.6\%).

Jadual 1. Profil responden

\begin{tabular}{lcc}
\hline Profil responden & Kekerapan & Peratus \\
\hline Jantina & 72 & \\
$\quad$ Lelaki & 29 & 71.3 \\
$\quad$ Perempuan & & 28.7 \\
Status perkahwinan & 6 & 5.9 \\
$\quad$ Bujang & 92 & 91.1 \\
Berkahwin & 3 & 3.0 \\
Bercerai & & \\
Bilangan anak & 12 & 11.9 \\
Tiada anak & 41 & 40.6 \\
1-2 orang & 41 & 40.6 \\
3-4 orang & 7 & 7.0 \\
5-7 orang & 15 & 14.9 \\
Umur & 27 & 26.7 \\
20-30 tahun & 40 & 39.6 \\
31-40 tahun & 19 & 18.8 \\
41-50 tahun & & \\
51 tahun ke atas & 13 & 42.9 \\
Tahap Pendidikan & 45 & 41.6 \\
Ijazah/Sarjana/Phd. & 42 & 1.0 \\
Sijil dan Vokasional & 1 & \\
Sekolah & & \\
Rendah/Menengah & & \\
Lain-lain &
\end{tabular}

\section{Profil perniagaan}

Jenis perniagaan yang diusahakan oleh responden adalah pelbagai, antaranya seperti bengkel membaiki kenderaan/motorsikal (42.6\%), perniagaan makanan $(27.7 \%)$, perniagaan kosmetik dan kedai runcit $(5.9 \%)$ dan selebihnya membuka kedai jahitan, kedai gunting rambut, kedai perabot, serta menjual alat telekomunikasi, alat tulis dan cenderamata perkahwinan. Majoriti responden telah menjalankan perniagaan kurang daripada 10 tahun (54.5\%) dan selebihnya telah beroperasi 11-20 tahun (39.6\%), melebihi 20 tahun (5.9\%).

Jadual 2 menunjukkan ringkasan profil perniagaan responden. Hampir keseluruhan responden yang menjalankan perniagaan milikan persendirian $(90.1 \%)$ diikuti oleh milikan perkongsian (5.9\%) dan milikan sendirian berhad (3.0\%). Jika dilihat kepada sumber modal, hampir keseluruhan responden (84.2\%) menggunakan modal sendiri untuk menjalankan perniagaan. Selebihnya pula mendapat bantuan kerajaan (8.9\%), pinjaman keluarga $(3.0 \%)$, sumber perniagaan lain $(3.0 \%)$ dan syarikat kewangan swasta (2.0\%). Sungguhpun ramai responden yang menggunakan modal sendiri, jumlah modal permulaan perniagaan adalah kecil (iaitu 58.4\% mempunyai modal permulaan maksimum sehingga RM5,000). Manakala 36.6 peratus responden memulakan perniagaan dengan modal antara RM5,000-RM50,000. Hanya sekitar lima peratus usahawan yang memulakan perniagaan dengan modal melebihi RM50,000. 
Jadual 2. Profil perniagaan

\begin{tabular}{|c|c|c|}
\hline Profil perniagaan & Kekerapan & Peratus \\
\hline \multicolumn{3}{|l|}{ Jenis hakmilik perniagaan } \\
\hline Persendirian & 91 & 90.1 \\
\hline Perkongsian & 6 & 5.9 \\
\hline Sendirian Berhad & 3 & 3.0 \\
\hline Lain-lain & 1 & 1.0 \\
\hline \multicolumn{3}{|l|}{ Sumber modal } \\
\hline Sendiri & 85 & 84.2 \\
\hline Perniagaan lain & 2 & 2.0 \\
\hline Pinjaman keluarga & 3 & 3.0 \\
\hline Institusi kerajaan & 9 & 8.9 \\
\hline Kewangan swasta & 2 & 2.0 \\
\hline \multicolumn{3}{|l|}{ Modal awal } \\
\hline RM1,000 dan ke bawah & 17 & 16.8 \\
\hline RM1,001-RM5,000 & 42 & 41.6 \\
\hline RM5,001-RM10,000 & 10 & 9.9 \\
\hline RM10,001-RM50,000 & 27 & 26.7 \\
\hline RM50,001 dan ke atas & 5 & 5.0 \\
\hline \multicolumn{3}{|l|}{ Bilangan pekerja (orang) } \\
\hline $1-4$ & 78 & 77.2 \\
\hline $5-10$ & 18 & 17.8 \\
\hline 11 dan ke atas & 5 & 5.0 \\
\hline \multicolumn{3}{|c|}{ Bilangan premis (anak syarikat): } \\
\hline 0 & 22 & 21.8 \\
\hline $1-2$ & 72 & 71.2 \\
\hline $3-4$ & 5 & 5.0 \\
\hline 5 dan ke atas & 2 & 2.0 \\
\hline \multicolumn{3}{|l|}{ Bilangan produk } \\
\hline $1-5$ & 78 & 77.3 \\
\hline $6-10$ & 17 & 16.8 \\
\hline 11 dan ke atas & 6 & 5.9 \\
\hline
\end{tabular}

Kebanyakan responden mempunyai bilangan pekerja antara 1-4 orang (77.2\%). Selebihnya mempunyai lima hingga 10 orang pekerja $(17.8 \%)$ dan hanya seorang responden sahaja mempunyai bilangan pekerja yang melebihi 10 orang. Majoriti responden mempunyai antara satu hingga dua unit bilangan premis/anak syarikat (71.1\%). Namun begitu, sebanyak 21.8 peratus responden tidak mempunyai bilangan premis/anak syarikat, yakni mereka beroperasi di satu tempat sahaja. Kajian turut mendapati seramai 77.3 peratus responden menghasilkan antara satu hingga lima jenis produk. Hal ini menunjukkan bahawa rata-rata responden mempunyai ciri usahawan yang inovatif kerana telah menghasilkan pelbagai produk dalam perniagaan mereka.

\section{Tahap kualiti keusahawanan}

Jadual 3 menunjukkan tahap kualiti keusahawanan responden yang meliputi cita-cita perniagaan, inovasi, kolaborasi dan inisiatif bagi mengembangkan perniagaan. Cita-cita perniagaan dapat dilihat daripada aspek pertumbuhan perniagaan yang berpunca daripada perancangan perniagaan mereka. Rata-rata responden $(71.3 \%)$ menyatakan 'Ya' bahawa perusahaan mereka mengalami keuntungan bagi tiga tahun kebelakangan. Selain itu, rata-rata responden $(75.2 \%)$ juga turut respon 'Ya' bahawa mereka merancang untuk pertumbuhan perusahaan mereka. Kedua-dua respon ini menunjukkan bahawa responden mempunyai keinginan dan motivasi intrisik sebagai 
seorang usahawan. Mereka mempunyai keinginan untuk mengembangkan perniagaan dan ianya merupakan salah satu faktor yang mempunyai hubungan dengan kualiti keusahawanan.

Jadual 3. Kualiti keusahawanan

\begin{tabular}{|c|c|c|c|}
\hline \multicolumn{2}{|c|}{ Indeks perlakuan 'sub-fungsi perangsang' } & \multirow{2}{*}{$\begin{array}{c}\text { Ya } \\
\text { Kekerapan (\%) } \\
\end{array}$} & \multirow{2}{*}{$\begin{array}{c}\text { Tidak } \\
\text { Kekerapan }(\%) \\
\end{array}$} \\
\hline i. & Cita-cita perniagaan: & & \\
\hline & Mengalami pertumbuhan & $72(71.3)$ & $29(28.7)$ \\
\hline & Merancang pertumbuhan perusahaan & $76(75.2)$ & $25(24.8)$ \\
\hline \multirow[t]{3}{*}{ ii. } & Inovasi: & & \\
\hline & Produk baru dihasilkan & $31(30.7)$ & $70(69.3)$ \\
\hline & Merancang produk baru & $53(52.5)$ & $48(47.5)$ \\
\hline \multirow[t]{3}{*}{ iii. } & Kolaborasi: & & \\
\hline & $\begin{array}{l}\text { Kerjasama/perjanjian rakan } \\
\text { niaga/pesaing }\end{array}$ & $24(23.8)$ & $77(76.2)$ \\
\hline & Jaringan bersama pelanggan/pembekal & $77(76.2)$ & $24(23.8)$ \\
\hline \multirow[t]{3}{*}{ iv. } & Inisiatif & & \\
\hline & Pelan jangka panjang dan sederhana & $85(84.2)$ & $16(15.8)$ \\
\hline & Menghantar pekerja kursus & $83(82.2)$ & $18(17.8)$ \\
\hline
\end{tabular}

Tahap kualiti keusahawanan juga boleh diukur daripada sikap berinovasi. Hasil kajian menunjukkanan hanya 30.7 peratus responden menjawab 'Ya' ada menghasilkan produk baru dalam tempoh tiga tahun kebelakangan. Sementara hanya separuh daripada responden (53.5\%) menjawab 'Ya' merancang untuk menghasilkan produk baru pada tahun hadapan. Dapatan ini menunjukkan bahawa responden masih lagi kurang terdedah dengan teknik dan proses penghasilan produk terkini ataupun mereka mempunyai hambatan lain yang menghalang mereka untuk jadi lebih berinovasi.

Kolaborasi oleh seseorang usahawan bersama rakan niaga, pembekal, pelanggan dan pesaing turut membolehkan tahap kualiti keusahawanan ditingkatkan. Terdapat sekitar 23.8 peratus responden manyatakan 'Ya" ada membuat perjanjian dengan rakan niaga dan persefahaman dengan pesaing dalam melakukan perniagaan. Sebaliknya, rata-rata responden (76.2\%) mengakui ada membuat jaringan/kerjasama usahawan dengan pelanggan/pembekal dalam menghasilkan produk.

Aspek keempat bagi menentukan tahap kualiti keusahawanan adalah inisiatif yang dilakukan oleh usahawan bagi meningkatkan prestasi perniagaannya. Kebanyakan responden (84.2\%) mempunyai pelan jangka sederhana dan panjang untuk perniagaan yang dijalankan. Malahan rata-rata responden $(82.2 \%)$ juga menjawab 'Ya' bahawa mereka menghantar pekerja berkursus untuk meningkatkan kemahiran dan kualiti pekerja mereka. Hal ini menunjukkan bahawa kebanyakan responden mempunyai kesedaran dan berusaha menjadi usahawan yang berjaya.

Jadual 4 menunjukkan tahap kualiti keusahawanan berdasarkan skor yang diperolehi responden. Seramai 23.7 peratus responden memperolehi skor antara 8 hingga 11, yakni mempunyai kualiti keusahawana yang rendah. Manakala seramai 53.5 peratus responden mendapat skor antara 12 hingga14 yang menunjukkan tahap kualiti keusahawanan mereka adalah sederhanan. Sementara itu, seramai 22.8 responden mendapat skor anatara 15 hingga 16 yang memberikan maksud mereka mempunyai tahap kualiti keusahawnan yang tinggi. Maka, dirumuskan bahawa tahap kualiti keusahawanan usahawan di Wilayah KEJORA adalah 'sederhana'. 
Jadual 4. Tahap kualiti keusahawanan

\begin{tabular}{lcc}
\hline Jumlah skor & Bilangan & Peratus \\
\hline 8-11 (Rendah) & 24 & 23.7 \\
12-14 (Sederhana) & 54 & 53.5 \\
15-16 (Tinggi) & 23 & 22.8 \\
\hline
\end{tabular}

Dapatan kajian ini adalah berbeza daripada kajian yang dilaksanakan oleh Santos et al. (2002) yang dijalankan di Seville, Sepanyol yang mendapati bahawa tahap kualiti keusahawanan di situ adalah 'rendah' dan berpunca daripada ketidaksediaan usahawan dalam mengharungi cabaran globalisasi. Bagi kes KEJORA pula, penambahbaikan yang boleh dibuat terutamanaya dengan menarik golongan profesional muda untuk kembali dan menjalankan perniagaan di Wilayah Pembangunan KEJORA telah meningkatkan setiap indeks kualiti keusahwanan terutamanya dari segi elemen inovatif kerana golongan profesional muda ini telah terdedah dengan teknologi terkini.

\section{Hubungan keperibadian usahawan dengan tahap kualiti keusahawanan}

Hasil ujian korelasi antara keperibadian usahawan dengan tahap kualiti keusahawanan menunjukkan terdapat perhubungan positif yang lemah dan signifikan $\left(\mathrm{r}_{\mathrm{s}}=0.354, p<0.01\right)$. Hal ini menunjukkan faktor keperibadian usahawan mempunyai hubungan positif dengan tahap kualiti keusahawanan, tetapi hubungan yang lemah. Bagi meningkatkan hubungan berkenaan, pihak KEJORA perlu menekankan program yang membabitkan pembangunan modal insan, terutamanya kepada golongan muda.

\section{Hubungan orientasi keusahawanan dengan tahap kualiti keusahawanan}

Secara keseluruhannya, hasil ujian korelasi di antara orentasi keusahawanan dengan tahap kualiti keusahawanan menunjukkan terdapat perhubungan positif yang sederhana dan signifikan $\left(\mathrm{r}_{\mathrm{s}}=0.543, p<0.01\right)$. Hal ini menunjukkan bahawa faktor orentasi keusahawanan mempunyai hubungan dengan tahap kualiti keusahawanan tetapi pada hubungan yang sederhana.

Jadual 5 menunjukkan hubungan orientasi keusahawanan dengan tahap kualiti keusahawanan berdasarkan elemen proaktif, inovatiof dan berani mengambil risiko. Wujud hubungan positif yang sederhana bagi elemen proaktif $\left(\mathrm{r}_{\mathrm{s}}=0.537, p<0.01\right)$ dengan tahap kualiti keusahawanan. Sementara itu, wujud hubungan positif yang lemah bagi elemen inovatif $\left(\mathrm{r}_{\mathrm{s}}=0.439, p<0.01\right)$ dan elemen berani mengambil risiko $\left(\mathrm{r}_{\mathrm{s}}=0.366, p<0.01\right)$ dengan tahap kualiti keusahawanan. Dapatan ini menunjukkan bahawa sikap usahawan yang proaktif mempunyuai hubungan yang sederhana dengan tahap kualiti keusahawanan.

Jadual 5. Hubungan orentasi keusahawanan dan tahap kualiti keusahawanan

\begin{tabular}{lcc}
\hline Faktor orentasi keusahawanan & Nilai korelasi & Tahap \\
\hline Proaktif & $0.537^{* *}$ & Sederhana \\
Inovatif & $0.439^{* *}$ & Lemah \\
Berani Mengambil Risiko & $0.366^{* *}$ & Lemah \\
\hline$*$ Korelasi adalah signifikan pada $\mathrm{p}<0.01$ & &
\end{tabular}


Berdasarkan dapatan ini, orientasi keusahawanan adalah salah satu elemen penting kepada pertumbuhan dan kejayaan perusahaan (Lumpkin \& Dess, 1996). Sikap usahawan yang proaktif dalam menjalankan perusahaan akan mengurangkan risiko kerana mereka mampu membuat persediaan daripada segi mental, kewangan dan bahan mentah. Sebaliknya, banyak syarikat muflis kerana usahawan tidak bersedia membuat penyesuaian perniagaan dengan keadaan semasa (Zafir \& Fazilah, 2007; Rohani et al., 2016).

\section{Hubungan Program Pembangunan Usahawan dengan tahap kualiti keusahawanan}

Hasil ujian korelasi di antara program pembangunan usahawan KEJORA dengan tahap kualiti keusahawanan menunjukkan terhadap perhubungan positif yang lemah dan signifikan $\left(\mathrm{r}_{\mathrm{s}}=0.371\right.$, $p<0.01)$. Dapatan ini menunjukkan faktor program pembangunan usahawan KEJORA mempunyai hubungan dengan tahap kualiti keusahawanan. Dapatan ini sama dengan dapatan Santos et al. (2002), iaitu program pembangunan usahawan yang dijalankan oleh pihak Kerajaan kurang hubungan dengan tahap kualiti keusahawanan. KEJORA seharusnya menjalankan program yang boleh meningkatkan kualiti keusahawanan dengan mengadakan program pendampingan bersama usahawan, program inkubator dan program mentor dengan usahawan berjaya bagi memimpin dan bergerak bersama usahawan yang baru bertapak.

\section{Kesimpulan}

Majoriti usahawan di KEJORA mempunyai tahap kualiti keusahawanan yang sederhana. Tahap kualiti keusahawanan usahawan pula didapati mempunyai hubungan dengan faktor keperibadian usahawan, orientasi usahawan dan program keusahawanan yang dilaksanakan oleh KEJORA. Selain itu, hasil kajian juga mendapati sikap proaktof, inovatif dan berani mengambil risiko mempunyai hubungan dengan peningkatan umur, tahap pendidikan dan bilangan tahun menjalankan perniagaan. Justeru, pihak KEJORA boleh meningkatkan lagi tahap kualiti keusahawanan dengan memberi perhatian kepada elemen inovasi dan kolaborasi. Selain itu, program pembangunan usahaawan KEJORA perlu diubahsuai dengan memberi fokus kepada kelemahan dan keperluan sebenar usahawan. Tahap kualiti keusahawanan usahawan di KEJORA boleh ditingkatkan melalui peningkatan dalam tahap pendidikan. Dalam masa yang sama, usahawan juga perlu mempunyai kecenderungan untuk menjadi lebih inovatif, membuat perancangan perniagaan dan berusaha mengembangkan perniagaanya dari masa ke semasa. iaitu matlamat akhir yang dilihat pada setiap kualiti keusahawanan.

\section{Penghargaan}

Penghargaan kepada Lembaga Kemajuan Johor Tenggara (KEJORA) atas kerjasama yang diberikan sepanjang kajian dilaksanakan. 


\section{Rujukan}

Abdullah Al Mamun, Rajennd Muniady, Mohd Asrul Hery Ibrahim, \& Noorshella Che Nawi. (2018). Effect of economic vulnerability on entrepreneurial competencies among Malaysian micro-entrepreneurs. Asia Pacific Journal of Innovation and Entrepreneurship, 12(2), 222237. https://doi.org/10.1108/APJIE-03-2018-0013

Basso, O., Alain, F., \& Bouchart, V. (2016). Entrepreneurial orientation: The making of a concept. International Journal of Entrepreneurship and Innovation, 10(4), 313-321.

Brown, T., Davidson, P., \& Wiklund, J. (2001). An opretaionalization of Stevenson's conceptualization of entrepreneurship as opportunity-based firm behavior. Strategic Management Journal, 22(10), 953-968.

Chowdry, F., Andretsch, D.B., \& Belitski, M. (2019). Institutions and entrepreneurship quality. Entrepreneurship Theories and Practice, 43(1), 51-81. https://doi.org/10.1177/1042258718780431.

Cooper, A.C., \& Dunkelberg, W.C. (1987). Entrepreneurial research: Old questions, new answers and methodological issues. American Journal of Small Business, 3, 11-23.

Darroch, M., \& Clover, T. (2005). Owners' perceptions of factors that constrain the survival and growth of small, medium and micro agribusinesses in KwaZulu-Natal, South Africa. Agrekon, 44(2), 238-263.

Diana Eraviaa, Tri Handayani, \& Julina. (2015). The opportunities and threats of small and medium enterprises in Pekanbaru: Comparison between SMEs in food and restaurant industries. Procedia - Social and Behavioral Sciences, 169, 88-97.

Gibb, A.A. (1993). The enterprise culture and education: Understanding enterprise education and its links with small business, entrepreneurship and wider educational goals. International Small Business Journal, 3(11), 11-34.

Guzman J. (1994). Towards a taxonomy of entrepreneurial theories. International Small Business Journal, 12(4), 77-88.

Guzman, J. (1995). A les petites enterprises et les petits entrepreneurs en Espagne. Une aproche qualitative. Revue International PME, 8, 121-137.

Guzman, J., \& Santos, F.J. (2001). The booster function entrepreneurial quality: An application to the province of Seville. Entrepreneurship and Regional Development, 13, 211-228.

Herron, L., \& Robinson, R.B. (1993). A structural model of the effects of entrepreneurial characteristics on venture performance. Journal of Business Venturing, 8(3), 281-294.

Kautonen, T., Kibler, E., \& Minniti, M. (2017). Late-career entrepreneurship, income and quality of life. Journal of Business Venturing, 32(3), 318-333. https://doi.org/ 10.1016/j.jbusvent.2017.02.005

Kementerian Kemajuan Luar Bandar dan Wilayah (KKLBW). (2012). Program Industri Luar Bandar. Retrieved from http://www.kklw.gov.my.

Koellinger, P., Minniti, M., \& Schade, C. (2007). "I think I can, I think I can" Overconfidence and entrepreneurial behavior. International Journal of Economic Psychology, 28(4), 502527. https://doi.org/10.1016/j.joep.2006.11.002.

Lembaga Kemajuan Wilayah Johor Tenggara (KEJORA). (2012). Laporan Tahunan 2011. Retrieved from http://www.kklw.gov.my.

Lembaga Kemajuan Wilayah Johor Tenggara (KEJORA). (2013). Laporan Tahunan 2012. Retrieved from http://www.kklw.gov.my. 
Lembaga Kemajuan Wilayah Johor Tenggara (KEJORA). (2014). Laman Utama dan Maklumat Program. Retrieved from http://www.kejora.gov.my/

Lembaga Kemajuan Wilayah Johor Tenggara (KEJORA). (2015). Laporan Tahunan 2014. Retrieved from http://www.kklw.gov.my.

Lumpkin, G.T., \& Dess, G.G. (1996). Clarifying the entrepreneurial orientation construct and linking it to performance. Academy of Management Review, 21(1), 135-172.

Malaysia. (2015). Eleventh Malaysia Plan. Government of Malaysia.

Manaf, A.A, Omar, N.H., Lee, K.Y., \& Ibrahim, F. (2012). Entreprenuers success in business: Some critical factors. International Business Management, 6(3), 369-373.

McCaffrey, M., (2009). Entrepreneurship, economic evolution, And the end of capitalism: reconsidering Schumpeter's thesis. The Quarterly Journal of Austrian Economics, 12(4), 321.

Osman, H. (2007). Faktor yang memperngaruhi kejayaan usahawan kredit mikro di Negeri Johor. Johor Bahru, Fakulti Pengurusan dan Pembangunan Sumber Manusia, Universiti Teknologi Malaysia.

Paco, A., Ferreira, J., \& Raposo, M. (2017). How to foster young scientists' entrepreneurial spirit? International Journal of Entrepreneurship, 21(1), 47-60.

Rohani Mohd, Badrul Hisham Kamaruddin, Mazzini Muda, Salwana Hassan, \& Khulida Kirana Yahya. (2016). Malay owner managers of SMEs: The Typology. Procedia Economics and Finance, 37, 86-92.

Santos J.F., Isidoro, R., \& Serano, J.F. (2012). SMEs and entrepreneurial quality from macro economic prospective. Management Decision, 50(8), 1382-1395. https://doi.org/10.1108/00251741211261980.

Santos, J.F., \& Francisco, L. (2002). Towards an empirical methodology for the measurement of the quality entrepreneur: the case of Sevillian entrepreneurs. $42^{\text {nd }}$ ERSA Conference. Dortmund ,Germany. 27-31 August.

Shane, S., Locke, E.A., \& Collins, C. (2012). Entrepreneurial motivation. Retrieved from http://digitalcommons.ilr.cornell.edu

Stanworth, J., \& Gray, C. (1991). Entrepreneurship and education: Action based research with training policy implications in Britain, ENDEC, Singapore. Retrieved from http://resourcelists.ntu.ac.uk

Wan Hussain, W.S. (2005). Mengurus perniagaan melalui etika: Satu perspektif pembangunan usahawan yang berjaya. Seminar Keusahawanan Islam Peringkat Kebangsaan 2005. 6 Sept. Retrieved from http://eprints.um.edu.my

Yaacob, M.R. (2012). Model usahawan Melayu berjaya: Kajian kes industri kitar semula di Pantai Timur Semenanjung Malaysia, Fakulti Keusahawanan dan Perniagaan, Universiti Malaysia KelantanVII. Prosiding PERKEM VII, 2, 770-779.

Zafir Mohd Makhbul, \& Fazilah Muhamad Hasun. (2007). Menjadi usahawan. Kuala Lumpur, PTS Professional Publishing.

Zhenfeng Ge, \& Ming Wang. (2017). A study of quality management of entrepreneurship practice teaching based on TQM. Open Access Library Journal, 4(7), 1-15. https://doi.org/10.4236/oalib.1103758

Zhou Hong, Tao Hong, ZhongCui, \& Wang Luzhuang. (2012). Entrepreneurship quality of college students related to Entrepreneurial Education: Empirical study on psychological and behavioral characteristics. Energy Procedia, 17, 1907-1913. https://doi.org/10.1016/j.egypro.2012.02.331. 